\title{
Klippel-Feil syndrome associated with aortic coarctation
}

\author{
Rodney H. Falk and John Mackinnon \\ From the Department of Cardiology, Dudley Road Hospital, Birmingham
}

A 13-year-old boy with aortic coarctation and Klippel-Feil syndrome is reported. This association has not been described previously.

The triad of low occipital hairline, limitation of neck movement, and fusion of cervical vertebrae was first described by Klippel and Feil (1912) and has come to bear their name. Since then a large number of cases have been described, some with associated congenital anomalies. These include 'Sprengel's' shoulder, rib anomalies, syringomyelia, and cardiac malformations (Menkes, 1974).

\section{Case report}

A 13-year-old boy was admitted for investigation of coarctation of the aorta. At the age of 2 he underwent a laparotomy for bleeding Meckel's diverticulum and the diagnosis of coarctation of the aorta was made at that time. He had no symptoms and school performance was normal. There was no family history of heart disease and his parents and younger brother were well.

On examination he was an intelligent, prepubertal boy, height $147 \mathrm{~cm}$ (30th centile) and weight $32 \mathrm{~kg}$ (10th centile). A short neck (Fig. 1) and low occipital hairline were noted but facial appearance was normal. There were no abnormalities of the palmar creases. Other relevant physical findings were limited to the cardiovascular system-radial pulses were equal and normal, femoral pulses were absent. The apex beat was not displaced and no thrills were palpable. A grade 2 systolic ejection murmur was audible all over the praecordium and over the scapulae. One collateral vessel was palpable over the right scapula. Blood pressure was $120 / 70$ $\mathrm{mmHg}(16 \cdot 0 / 9 \cdot 3 \mathrm{kPa})$ in both arms. Fundi were normal.

Chest $x$-ray film showed early rib notching and there was fusion of the second and third ribs on the right.

Electrocardiogram showed left ventricular hypertrophy by voltage criteria.
In view of his age, aortography was performed under general anaesthesia. At induction, endotracheal intubation proved impossible because of limited extension of the neck and anaesthesia was maintained with a face mask.

Angiography revealed aortic coarctation distal to the left subclavian artery.

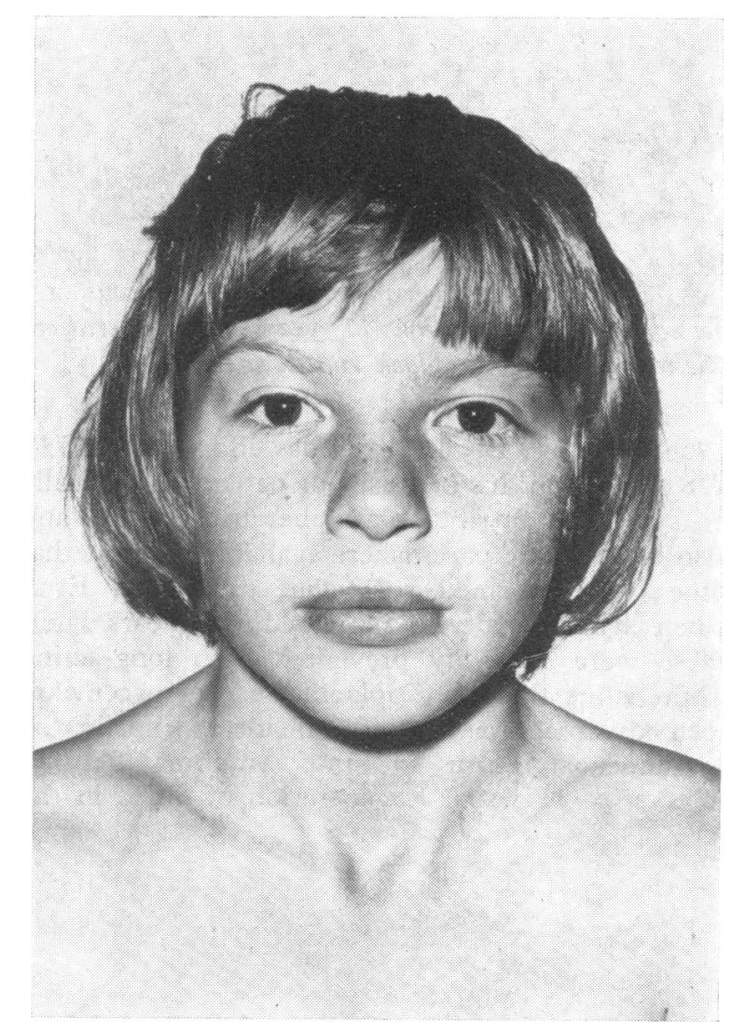

FIG. 1 The short neck of Klippel-Feil syndrome. 
An $x$-ray film of the cervical spine (Fig. 2) showed fusion of the third and fourth cervical vertebrae and abnormalities of the apophysial joints of $\mathrm{C} 2$ and C3. Chromosome analysis of the peripheral blood gave normal results.

Operation was carried out at Walsgrave Hospital by Mr. W. G. Williams. Intubation proved difficult but was eventually achieved in the usual way. There was a severe coarctation rising immediately from the aortic arch, with no proximal segment above the coarctation. The aorta was hypoplastic but not unusual for coarctation. An incision was made in the coarctation extending from the descending aorta to the left subclavian artery and a large 'dacron' patch inserted, with resulting abolition of the gradient across the coarctation. He made an uninterrupted recovery.

\section{Discussion}

A detailed account and review of the published reports on Klippel-Feil syndrome appeared in 1968 (Morrison, Perry, and Scott). These authors collected 19 cases with associated cardiac anomalies out of a total of 503 cases and added 2 cases of their own, giving an incidence of associated cardiac anomalies of $4 \cdot 2$ per cent. Among these 21 cases was a variety of congenital cardiac defects, ventricular septal defect being the commonest (8 cases). No patient had aortic coarctation and none was known to have had a Meckel's diverticulum.

Coarctation of the aorta has a well-known associa- tion with chromosomal abnormalities such as Down's syndrome, Turner's syndrome, trisomy 10, and trisomy 13-15. The so-called 'male Turner's syndrome' or Noonan's syndrome is associated with short stature and hypogonadism in males, with a normal sex chromosome complement. There is, however, no increased incidence of aortic coarctation, but pulmonary stenosis may be a feature. Mental retardation is common and webbed neck and cubitus valgus are features. No cervical fusion has been described (Smith, 1970).

In view. of the reported increased incidence of congenital heart lesions in Klippel-Feil syndrome and their heterogeneity, it is likely that the association in this patient is genuine rather than fortuitous.

\section{References}

Klippel, M., and Feil, A. (1912). Un cas d'absence des vertèbres cervicales, cage thoracique remontant jusqu'à la base du crâne. Bulletins et Mémoires de la Société d'Anthropologie de Paris, 6, s., iii, 101.

Menkes, J. H. (1974). Textbook of Child Neurology. Lea and Febiger, Philadelphia.

Morrison, S. G., Perry, L. W., and Scott, L. P. (1968). Congenital brevicollis (Klippel-Feil syndrome and cardiovascular anomalies). American fournal of Diseases of Children, 115, 614.

Smith, D. W. (1970). Recognizable Patterns of Human Malformation. W. B. Saunders, Philadelphia.

Requests for reprints to Dr. John Mackinnon, Dudley Road Hospital, P.O. Box 293, Dudley Road, Birmingham B18 7QH.

FIG. 2 X-ray film of the cervical spine showing fusion of the third and fourth vertebrae. 